\title{
Carbohydrate intake and incidence of type 2 diabetes in the European Prospective Investigation into Cancer and Nutrition (EPIC)-Potsdam Study
}

\author{
Matthias B. Schulze*, Mandy Schulz, Christin Heidemann, Anja Schienkiewitz, Kurt Hoffmann \\ and Heiner Boeing \\ Department of Epidemiology, German Institute of Human Nutrition Potsdam-Rehbruecke, Arthur-Scheunert-Allee 114-116, \\ 14558 Nuthetal, Germany
}

(Received 15 May 2007 - Revised 14 September 2007 - Accepted 17 September 2007 - First published online 8 November 2007)

It remains unclear what long-term effects of substituting carbohydrates at the expense of protein or fat may have with regard to diabetes risk. Our objective was to evaluate carbohydrate intake in predicting type 2 diabetes using substitution models for fat and protein. We conducted a prospective cohort study of 9702 men and 15365 women aged 35-65 years and free of diabetes at baseline (1994-8) who were followed for incident type 2 diabetes until 2005. Dietary intake of macronutrients was estimated with a validated FFQ. We estimated the relative risk (RR) using Cox proportional hazards analysis. During 176117 person-years of follow-up we observed 844 incident cases of physician-confirmed type 2 diabetes. After adjustment for age, BMI, waist circumference, potential lifestyle and dietary confounders, substituting $5 \%$ of energy intake from total, saturated, or monounsaturated fat with carbohydrates was not associated with diabetes risk. In contrast, substituting carbohydrates for protein or PUFA was inversely related to diabetes risk (RR for $5 \%$ energy substitution of protein 0.77 (95\% CI 0.64, 0.91); RR for PUFA 0.83 (95\% CI 0.70, 0.98)) These associations appeared to be similar for men and women, but gained statistical significance only among men for protein (RR 0.78 (95\% CI $0.61,0.99))$. Restricted cubic spline regression did not indicate non-linearity of these associations $(P$ for non-linearity in full cohort was 0.353 and 0.349). In conclusion, a higher carbohydrate intake at the expense of protein and PUFA might be associated with decreased diabetes risk.

Carbohydrates: Diet: Incidence: Type 2 diabetes mellitus: Prospective studies

While obesity and lifestyle characteristics such as physical activity are established risk factors for type 2 diabetes ${ }^{(1,2)}$, less is known about dietary factors. The quantity of carbohydrates has received particular interest, as high-carbohydrate diets generally produce high postprandial glucose and insulin responses. However, the total percentage of energy derived from carbohydrates in the diet has generally not been found to predict diabetes risk in prospective studies ${ }^{(3-8)}$. Previous studies largely ignored that differences in carbohydrate intake in isoenergetic settings reflect substitutions for other macronutrients ${ }^{(3-6,8)}$. Substituting carbohydrates for protein or fat or different fatty acids may have very different metabolic consequences beyond glucose responses. For example, HDL-cholesterol blood levels, which are a potent predictor of diabetes risk $^{(9-11)}$, depend on the macronutrient composition with distinct effects of different fatty acids ${ }^{(12)}$. The intake of $n-3$ PUFA may regulate adiponectin secretion ${ }^{(13)}$, which is strongly related to diabetes risk ${ }^{(14)}$. In addition, protein-rich foods are known to increase postprandial insulin secretion without augmenting glucose concentrations ${ }^{(15,16)}$. Analysing the association between carbohydrate intake and diabetes risk in statistical models, which take into consideration the other nutrients that carbohydrates are substituted with $^{(17,18)}$, may help clarify this complex relationship.
We aimed to evaluate the association between carbohydrate intake and risk of type 2 diabetes, using macronutrient substitution models in a large prospective cohort study of men and women.

\section{Materials and methods}

\section{Study population}

The European Prospective Investigation into Cancer and Nutrition (EPIC)-Potsdam study involves 27548 subjects, 16644 women aged mainly 35-65 years and 10904 men aged mainly 40-65 years, from the general population of Potsdam, Germany, recruited between 1994 and $1998^{(19,20)}$. The baseline examination included anthropometric measurements as well as a personal interview and a questionnaire on prevalent diseases and socio-demographic and lifestyle characteristics. Follow-up questionnaires have been administered every $2-3$ years. Response rates for follow-up rounds 1, 2, 3 and 4 were 96, 95, 91 and $90 \%$ (by 31 August 2005).

The prevalence of diabetes mellitus at baseline was evaluated by a physician using information on self-reported medical diagnoses, medication records and dieting behaviour. Uncertainties regarding a proper diagnosis were clarified 
with the participant or treating physician. After exclusion of participants with prevalent diabetes at baseline or with self-reported diabetes during follow-up but without physician confirmation ( $n$ 1567), with missing follow-up time ( $n$ 589), with missing diet and confounder information at baseline (n 226), or with implausible energy intake below $3350 \mathrm{~kJ}$ $(800 \mathrm{kcal})$ or above $25100 \mathrm{~kJ}(6000 \mathrm{kcal})$ per $\mathrm{d}(n 99)$, a total of 9702 men and 15365 women remained for analyses.

\section{Ascertainment of type 2 diabetes}

Potentially incident cases of diabetes were identified in each follow-up questionnaire via self-reports of a diabetes diagnosis, diabetes-relevant medication or dietary treatment due to diabetes. All potentially incident cases of diabetes were verified by questionnaires mailed to the diagnosing physician asking about the date and type of diagnosis, diagnostic tests, and treatment of diabetes. Only cases with a physician diagnosis of type 2 diabetes (International Statistical Classification of Diseases (ICD10) code E11) and a diagnosis date after the baseline examination were considered as confirmed incident cases of type 2 diabetes.

\section{Dietary assessment}

All participants were asked to complete a semi-quantitative FFQ which assessed the average frequency of intake and the portion size of 148 foods consumed during the 12 months before examination. Frequency of intake was measured using ten categories, ranging from 'never' to 'five times per day or more'. Portion sizes were estimated using photographs of standard portion sizes. Information on frequency of intake and portion size was used to calculate the amount of each food item in g consumed on average per $d$. Nutrient intake was calculated according to the German Food Code and Nutrient Data Base ${ }^{(21)}$ version II.3. Intakes estimated from the FFQ at baseline were calculated in $\mathrm{g} / \mathrm{d}$. These intakes were then calibrated to account for systematic over- or underestimation. Here, the single $24 \mathrm{~h}$ recalls of the EPIC calibration study with 2297 participants were used as the reference instrument ${ }^{(22,23)}$. Before calibration, intake from the single $24 \mathrm{~h}$ recall was shrunken to the sex- and age-group-specific mean using the external within-person variance estimate from another calibration study with repeated $24 \mathrm{~h}$ recalls. Shrinkage excludes the intra-individual variance component and the shrunken intake values can be considered as estimates of habitual dietary intake. Then, a linear calibration method was applied ensuring that the mean and the variance of the calibrated FFQ data are equal to the mean and variance of estimated habitual dietary intake from $24 \mathrm{~h}$ recalls. Intakes of macronutrients were expressed as absolute intake $(\mathrm{g} / \mathrm{d})$ and nutrient density ( $\%$ of total energy intake); fibre and $\mathrm{Mg}$ intake were adjusted for total energy intake using the residual method $^{(24)}$. The deattenuated correlation coefficients between non-calibrated FFQ and twelve $24 \mathrm{~h}$ dietary recalls for energy-adjusted intake of carbohydrates was 0.58 for total carbohydrates, 0.66 for monosaccharides, 0.65 for disaccharides and 0.65 for polysaccharides ${ }^{(25,26)}$.

\section{Assessment of lifestyle exposures}

Information on educational attainment, smoking, occupational activity level and leisure-time physical activity were assessed with a self-administered questionnaire and a personal interview. We considered sport activities and biking as leisuretime activities, both calculated as the average time spent per week during the 12 months before baseline recruitment. Anthropometric measurement procedures followed standard protocols under strict quality control ${ }^{(27,28)}$.

\section{Statistical analyses}

We estimated the relative risk (RR) for each quintile of carbohydrate intake compared with the lowest quintile using Cox proportional hazards analysis stratified by age. Age was used as the primary time-dependent variable in all models, with entry time defined as the subject's age at recruitment and exit time as the date of diagnosis of diabetes, death, or return of the last follow-up questionnaire. We used information on covariates obtained from the baseline examination in multivariate analyses, including sex, education, occupational activity, sport activity, biking, smoking, total energy intake and alcohol intake. Additional adjustments were made for BMI and waist circumference as well as fibre intake, $\mathrm{Mg}$ intake, and the PUFA:SFA and MUFA:SFA ratios. In multivariate nutrient-density models ${ }^{(29)}$, we simultaneously included energy intake, the percentages of energy derived from carbohydrates and alcohol and other potentially confounding variables. We also considered energy densities of protein, total fat and fatty acids. The coefficients from these models can be interpreted as isoenergetic substitution of $5 \%$ of energy from carbohydrates for the same percentage of energy from protein, fat or specific fatty acids. Restricted cubic spline regression was used to examine non-linearity of the RR function for nutrient-density data ${ }^{(30)}$ using the SAS Macro RCS ${ }^{(31)}$. Four knots were selected separately for men and women according to the 5th, 25th, 75th and 95th percentiles of carbohydrate intake. The reference value was fixed at $45 \%$ energy contribution from carbohydrates. Analyses were stratified by sex and were performed with SAS release 9.1 (SAS Institute, Cary, NC, USA).

\section{Results}

At baseline, subjects with higher carbohydrate intake were older, cycled more frequently, had a lower prevalence of smoking but a lower educational level (Table 1). Men with high carbohydrate intake had lower BMI and waist circumferences, while anthropometry was not related to carbohydrate intake among women. With regard to diet, participants with higher carbohydrate intake had higher intakes of fibre and $\mathrm{Mg}$ and lower intake of fat, protein and alcohol.

During 176117 person-years of follow-up we observed 844 incident cases of type 2 diabetes (491 men and 353 women). The crude incidence of diabetes increased with increasing age and was higher among men than women (Fig. 1). To evaluate the association between carbohydrate intake and diabetes risk, we first used multivariate nutrient-density models expressing carbohydrate intake as percentage of total energy intake. A higher carbohydrate intake was associated with a 
Table 1. Baseline characteristics by quintiles of carbohydrate intake (\% energy) among men and women in the European Prospective Investigation into Cancer and Nutrition-Potsdam Study, 2005 (Mean values or percentages)

\begin{tabular}{|c|c|c|c|c|c|c|c|c|c|c|c|c|}
\hline \multirow[b]{3}{*}{ Characteristic } & \multicolumn{6}{|c|}{ Men } & \multicolumn{6}{|c|}{ Women } \\
\hline & \multicolumn{5}{|c|}{ Quintiles of carbohydrate intake (\% energy) } & \multirow[b]{2}{*}{$P$} & \multicolumn{5}{|c|}{ Quintiles of carbohydrate intake (\% energy) } & \multirow[b]{2}{*}{$P$} \\
\hline & 1 & 2 & 3 & 4 & 5 & & 1 & 2 & 3 & 4 & 5 & \\
\hline Carbohydrate intake (\% energy) & $30 \cdot 2$ & $35 \cdot 2$ & 38.4 & 41.6 & $47 \cdot 3$ & $<0.001$ & $36 \cdot 0$ & $41 \cdot 1$ & 44.1 & 47.1 & $52 \cdot 3$ & $<0.001$ \\
\hline Age (years) & 49.8 & $51 \cdot 3$ & 51.9 & 52.5 & $52 \cdot 6$ & $<0.001$ & 47.6 & 47.8 & 48.0 & 48.5 & 49.8 & $<0.001$ \\
\hline BMI $\left(\mathrm{kg} / \mathrm{m}^{2}\right)$ & $27 \cdot 2$ & $26 \cdot 9$ & $26 \cdot 7$ & $26 \cdot 8$ & $26 \cdot 7$ & $<0.001$ & $25 \cdot 8$ & 25.5 & $25 \cdot 6$ & $25 \cdot 6$ & $25 \cdot 7$ & 0.376 \\
\hline Waist circumference $(\mathrm{cm})$ & 95.4 & 94.8 & $94 \cdot 1$ & 94.1 & 93.6 & $<0.001$ & $80 \cdot 8$ & 79.8 & $80 \cdot 0$ & $80 \cdot 1$ & $80 \cdot 2$ & 0.094 \\
\hline Sport activities (h/week) & 1.0 & 1.0 & 1.0 & 1.0 & 1.1 & 0.289 & 0.9 & 0.9 & 1.0 & 0.9 & 1.0 & 0.221 \\
\hline Cycling (h/week) & 1.5 & 1.7 & 1.9 & 1.8 & $2 \cdot 0$ & $<0.001$ & 1.7 & 1.7 & 1.9 & 1.9 & $2 \cdot 2$ & $<0.001$ \\
\hline Smoking (\%) & & & & & & $<0.001$ & & & & & & $<0.001$ \\
\hline Never & $25 \cdot 9$ & $28 \cdot 1$ & 31.7 & $32 \cdot 8$ & 38.3 & & 48.4 & 55.9 & 59.9 & $62 \cdot 3$ & 63.4 & \\
\hline Former & 43.7 & $45 \cdot 2$ & 43.8 & 44.4 & $42 \cdot 2$ & & $27 \cdot 9$ & 25.4 & $23 \cdot 6$ & 22.5 & 21.7 & \\
\hline Current $<20$ cigarettes $/ \mathrm{d}$ & $15 \cdot 8$ & $16 \cdot 2$ & $16 \cdot 5$ & $15 \cdot 8$ & 12.0 & & $18 \cdot 3$ & $15 \cdot 4$ & 14.0 & 12.8 & 12.4 & \\
\hline Current $20+$ cigarettes $/ \mathrm{d}$ & 14.6 & 10.6 & 8.0 & $7 \cdot 0$ & $7 \cdot 6$ & & 5.4 & 3.3 & 2.5 & $2 \cdot 3$ & 2.5 & \\
\hline Educational attainment (\%) & & & & & & 0.024 & & & & & & $<0.001$ \\
\hline No or in training & 1.3 & 1.9 & 1.4 & $2 \cdot 0$ & 1.9 & & 3.7 & 3.7 & 3.8 & 4.1 & $5 \cdot 2$ & \\
\hline Vocational training & 31.6 & 29.9 & $29 \cdot 1$ & 33.3 & 32.9 & & $35 \cdot 7$ & 37.1 & 36.4 & 37.0 & 37.4 & \\
\hline Technical school & $16 \cdot 8$ & $18 \cdot 0$ & $15 \cdot 9$ & $17 \cdot 2$ & $16 \cdot 4$ & & $29 \cdot 6$ & $29 \cdot 6$ & 28.9 & 29.9 & $32 \cdot 0$ & \\
\hline Technical college, university & $50 \cdot 3$ & $50 \cdot 2$ & 53.6 & 47.6 & 48.8 & & 31.0 & $29 \cdot 6$ & 30.9 & $29 \cdot 0$ & $25 \cdot 5$ & \\
\hline Occupational activity (\%) & & & & & & 0.021 & & & & & & $<0.001$ \\
\hline Light & $58 \cdot 2$ & 57.2 & 58.5 & 55.0 & 54.4 & & 64.4 & $63 \cdot 2$ & $62 \cdot 8$ & 61.4 & $58 \cdot 2$ & \\
\hline Moderate & 28.9 & 30.9 & $31 \cdot 0$ & 33.1 & $32 \cdot 7$ & & 31.4 & 34.2 & 33.4 & 34.9 & 37.6 & \\
\hline Heavy & $13 \cdot 0$ & $12 \cdot 0$ & $10 \cdot 6$ & 11.9 & $12 \cdot 9$ & & $4 \cdot 2$ & $2 \cdot 7$ & 3.8 & 3.7 & $4 \cdot 2$ & \\
\hline Energy intake (kJ) & 10950 & 10786 & 10585 & 10489 & 10000 & $<0.001$ & 7439 & 7393 & 7418 & 7351 & 7205 & $<0.001$ \\
\hline Protein intake (\% energy) & 14.6 & $14 \cdot 1$ & $13 \cdot 8$ & 13.4 & $13 \cdot 2$ & $<0.001$ & 14.8 & 14.4 & $14 \cdot 0$ & 13.7 & $13 \cdot 1$ & $<0.001$ \\
\hline Fat intake (\% energy) & $45 \cdot 8$ & $43 \cdot 1$ & 41.6 & 39.7 & 35.4 & $<0.001$ & 42.9 & $40 \cdot 6$ & 38.7 & $36 \cdot 7$ & 32.6 & $<0.001$ \\
\hline Alcohol intake (\% energy) & 9.5 & 7.7 & $6 \cdot 3$ & $5 \cdot 2$ & $4 \cdot 1$ & $<0.001$ & $6 \cdot 3$ & 3.9 & $3 \cdot 2$ & 2.5 & $2 \cdot 0$ & $<0.001$ \\
\hline Fibre intake $(\mathrm{g} / \mathrm{d})$ & $14 \cdot 0$ & $16 \cdot 9$ & 18.4 & 19.9 & 21.6 & $<0.001$ & 17.7 & 19.7 & 20.5 & $21 \cdot 3$ & 22.1 & $<0.001$ \\
\hline Mg intake $(\mathrm{mg} / \mathrm{d})$ & 292 & 297 & 299 & 302 & 317 & $<0.001$ & 296 & 302 & 307 & 312 & 323 & $<0.001$ \\
\hline PUFA:SFA ratio & 0.48 & 0.47 & 0.47 & 0.46 & 0.46 & $<0.001$ & 0.45 & 0.44 & 0.44 & 0.43 & 0.43 & 0.30 \\
\hline MUFA:SFA ratio & 0.86 & 0.84 & 0.84 & 0.83 & 0.92 & 0.293 & 0.83 & 0.82 & 0.82 & 0.82 & 0.83 & $<0.001$ \\
\hline
\end{tabular}




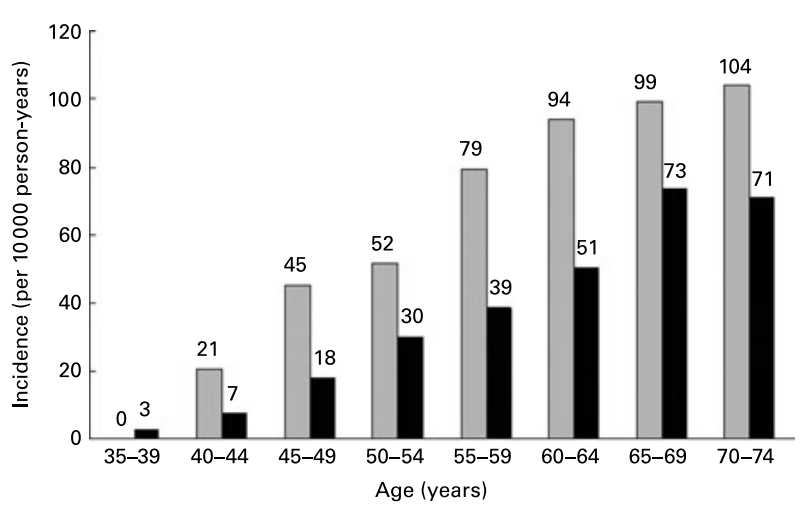

Fig. 1. Incidence rate (per 10000 person-years) of type 2 diabetes mellitus among men ( $\square$ ) and women ( $\square$ ) for different age groups in the European Prospective Investigation into Cancer and Nutrition-Potsdam Study, 2005.

lower risk of diabetes in age-adjusted models among men (Table 2). The RR for the highest quintile compared with the lowest was 0.71 (95\% CI 0.54, 0.94). This association was attenuated controlling for lifestyle confounders as well as BMI and waist circumference (RR 0.83 (95\% CI 0.62 , 1.12)). This association was further attenuated after controlling for the intake of $\mathrm{Mg}$, fibre, the PUFA:SFA ratio and the MUFA:SFA ratio (RR 0.91 (95\% CI 0.66, 1.26); $P=0.78$ for trend). Associations among women were very similar, although they did not gain statistical significance in any model. In the full adjusted model, the RR for extreme quintiles was 0.89 (95\% CI $0.62,1.29 ; P=0.64$ for trend).

We further used different multivariate nutrient-density models to model specific energy substitution. Exchanging carbohydrates for total fat was not associated with diabetes risk (Fig. 2). Similarly, exchanging carbohydrates for SFA or MUFA was not significantly related to diabetes risk. However, a $5 \%$ higher energy contribution by carbohydrates at the expense of PUFA and protein was significantly associated with a lower risk of developing type 2 diabetes. The RR among all participants was $0.83(95 \%$ CI $0.70,0.98)$ for $5 \%$ energy at the expense of PUFA and 0.77 (95\% CI 0.64, 0.91 ) for $5 \%$ energy at the expense of protein. These associations appeared to be similar for men and women, but reached statistical significance only among men for protein (RR 0.78 (95\% CI $0.61,0.99)$ ). When we restricted the analysis to participants with moderate to high carbohydrate intakes $(\geq 45 \%$ energy) the inverse association for a carbohydrate-for-protein substitution remained statistically significant (RR 0.64 $(95 \%$ CI 0.43, 0.96)). While the association for the carbohydratefor-PUFA substitution remained similar, it was not statistically significant anymore (RR 0.67 (95\% CI 0.43, 1.04)). Restricted cubic spline regression was used to examine non-linearity of these RR functions (Fig. 3). There was no indication for an association between a carbohydrate-for-fat substitution at any carbohydrate intake level (Fig. 3 (A)). In contrast, carbohydrate-for-protein (Fig. 3 (B)) and carbohydrate-for-PUFA (Fig. 3 (C)) substitutions were inversely related to diabetes risk with no indication for non-linearity $(P=0.353$ and $0.349)$. The inverse associations between a carbohydrate-forprotein and a carbohydrate-for-PUFA substitution appeared to be slightly stronger at low carbohydrate intake levels among men (data not shown). However, tests for non-linearity were non-significant $(P=0 \cdot 127$ and $0 \cdot 127)$. There was also no indication of non-linearity among women $(P=0.565$ and 0.561). We further examined whether these associations remained similar in subgroup analyses based on BMI and the reported energy intake:BMR ratio. Associations appeared to be stronger among non-obese participants (data not shown). However, tests for interaction were non-significant. We also repeated the analyses using models without adjustment for total energy intake, BMI and waist circumference, but this had minimal impact on our observations. The RR was 0.82 (95\% CI $0.70,0.97)$ for $5 \%$ energy from carbohydrates at the expense of PUFA and 0.77 (95\% CI 0.65 , 0.91 ) for $5 \%$ energy from carbohydrates at the expense of protein in multivariate models not controlling for total energy intake. Using models not controlling for total energy intake, BMI, and waist circumference, the RR were 0.81 (95\% CI $0.69,0.95)$ for $5 \%$ energy carbohydrate-for-PUFA substitution and $0.61(95 \%$ CI $0.51,0.72)$ for $5 \%$ energy carbohydrate-for-protein substitution.

The age-adjusted RR for the highest quintile compared with the lowest quintile of absolute intake $(\mathrm{g} / \mathrm{d})$ of carbohydrates among men was 0.75 (95\% CI $0.56,1.00 ; P=0.026$ for trend; Table 3). This association was stronger controlling for lifestyle confounders (RR 0.53 (95\% CI 0.34, 0.85); $P=0.005$ for trend), but was not significant after adjustment for anthropometric and diet characteristics (RR 0.67 (95\% CI $0.41,1.08) ; P=0.104$ for trend). Similar associations were observed among women, but were not statistically significant (Table 3). We further evaluated whether different types of carbohydrates are related to diabetes risk. After adjustment for lifestyle confounders, anthropometry and diet characteristics, starch, sucrose, glucose and fructose were not significantly associated with diabetes risk in men or women (Table 4).

\section{Discussion}

We found that among men and women, a substitution of protein with carbohydrates was associated with a reduced risk of type 2 diabetes independently of age, anthropometry, alcohol consumption, physical activity and other lifestyle risk factors. Higher carbohydrate intake at the expense of total fat was not related to risk; however, substituting carbohydrates for PUFA was also associated with a lower diabetes risk.

Several previous cohort studies have evaluated whether carbohydrate intake is associated with the incidence of type 2 diabetes $^{(3-8)}$. After multivariate adjustment, none of the previous studies has observed a significant association. However, in contrast to the present study, most previous studies did not evaluate specific macronutrient substitutions. In the Nurses' Health Study II, an isoenergetic substitution of carbohydrates for protein was evaluated, but in contrast to the present study, no significant association was observed ${ }^{(7)}$. Our finding, that substituting carbohydrates for PUFA reduces diabetes risk is in contrast to findings from the Nurses' Health Study, where women in the highest quintile of PUFA intake were at lower risk of developing diabetes controlling for protein, alcohol, and other fatty acids, thus modelling a substitution of PUFA for carbohydrates ${ }^{(32)}$. Although we also evaluated absolute carbohydrate intake, multivariate nutrient-density models may be particularly valuable if similar effects of an increment in intake for subjects with high and low energy intakes may 
not be plausible ${ }^{(29)}$. In addition, under isoenergetic settings assuming a steady state of energy balance, thus without changing the amount of energy consumed, it is impossible to change intake of one macronutrient without changing at least one other macronutrient. Macronutrient intake is therefore generally characterised by substitutions. As a consequence, observed associations cannot be interpreted as the effect of one single nutrient, but rather as a combination of two or more nutrients. It should be noted that energy excess and subsequent weight gain are important causes of type 2 diabetes. It could therefore be argued that adjustment for energy intake would represent over-control of a variable in the causal pathway. However, the multivariate nutrient density allows us to evaluate whether carbohydrate intake is related to diabetes risk independent of its contribution to energy intake per se. In this sense, the model is conceptually similar to metabolic studies, where, for example, changes in lipoproteins were evaluated when carbohydrates constituting a particular amount of dietary energy are replaced isoenergetically with fat or specific fatty acids ${ }^{(12)}$.

We did not observe a significant association between the intake of starch and diabetes risk. In the Women's Health Study $^{(33)}$ and the Iowa Women's Study ${ }^{(5)}$, non-significant inverse associations between starch intake and diabetes risk were observed ${ }^{(33)}$, while starch intake was positively associated with risk in the Melbourne Collaborative Cohort Study after adjustment for BMI and waist:hip ratio ${ }^{(6)}$. Cohort studies on the role of starch intake in the development of diabetes are therefore inconclusive so far. We also found no significant association between sucrose intake and diabetes risk. Although previous studies are inconsistent, there is some suggestion that sucrose intake might be inversely associated with diabetes risk. No significant association between sucrose consumption and diabetes risk was observed in the Nurses' Health Study ${ }^{(34)}$. However, higher sucrose intake was inversely associated with risk in the Women's Health Study after excluding participants with a history of hypertension and hypercholesterolaemia ${ }^{(33)}$. Similarly, higher sucrose intake was significantly inversely associated with risk in the Iowa Women's Study ${ }^{(5)}$. Sugars were also inversely associated with diabetes risk in the Melbourne Collaborative Cohort Study after adjustment for obesity ${ }^{(6)}$, although the role of specific sugars remains unclear from this study. The finding of an inverse association between higher sucrose consumption and diabetes risk by some cohort studies is in contrast to experiments in human subjects, which have produced very conflicting results, and experimental research on animals, which has shown a clear and consistent effect of high-sucrose diets in decreasing insulin sensitivity ${ }^{(35)}$. Glucose and fructose were not associated with risk in our cohort, similar to findings from the Women's Health Study ${ }^{(33)}$. However, significant positive associations with diabetes risk were observed for glucose and fructose in the Iowa Women's Study ${ }^{(5)}$. Similarly, frequent consumption of sugar-sweetened soft drinks containing high-fructose maize syrup and thus providing large amounts of fructose and glucose has been related to higher diabetes risk $^{(36)}$. Still, the inconsistency across studies may result from different effects from sugars consumed as added sugar $v$. those naturally occurring in foods.

Although protein acts as an insulin secretagogue ${ }^{(15,16)}$, and stimulation of insulin secretion counterbalances the increased 


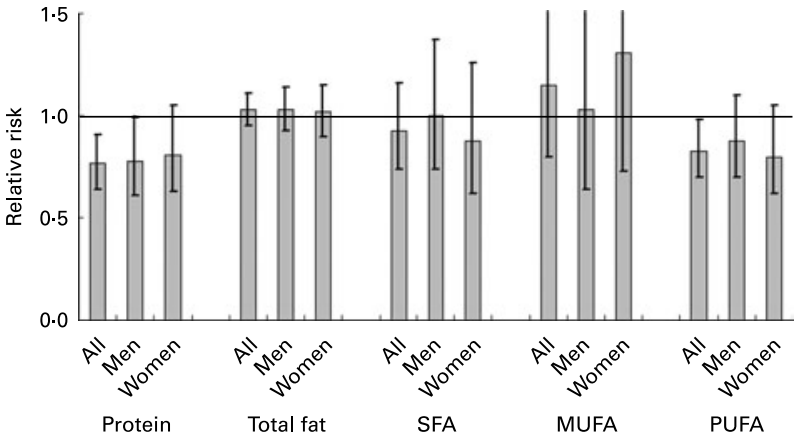

Fig. 2. Relative risk of type 2 diabetes for isoenergetic substitution of $5 \%$ energy with carbohydrates for other macronutrients among all participants, men and women in the European Prospective Investigation into Cancer and Nutrition-Potsdam Study, 2005. The models were adjusted for age, education (in or no training, vocational training, technical school, or technical college or university degree), occupational activity (light, moderate, heavy), sport activity $(0,0 \cdot 1-4 \cdot 0,>4 \cdot 0 \mathrm{~h} /$ week $)$, cycling $(0,0 \cdot 1-2 \cdot 4,2 \cdot 5-4 \cdot 9, \geq 5 \mathrm{~h} /$ week $)$, smoking (never, past, current $<20$ cigarettes/d, current $\geq 20$ cigarettes/d), alcohol intake, total energy intake, fibre intake, and Mg intake. Models for total fat and protein intake were also adjusted for PUFA:SFA ratio, and MUFA:SFA ratio. Models for all study participants were also adjusted for sex. Vertical bars represent $95 \% \mathrm{Cl}$.

gluconeogenesis due to postprandial amino acid elevations, the gluconeogenic effect of amino acids might be substantial in subjects with impaired insulin secretion ${ }^{(37,38)}$. In addition, short-term amino acid infusion induces peripheral insulin resistance in healthy humans by inhibition of glucose transport and phosphorylation and subsequent reduction in glycogen synthesis ${ }^{(39)}$. This has led to the notion that protein-rich diets contribute to the disturbance of carbohydrate metabolism $^{(40)}$, although trials on low-carbohydrate high-protein diets have generally not shown such effects ${ }^{(41)}$; regarding the effects of protein on HDL-cholesterol concentrations, data are not conclusive so far $^{(42)}$. Still, the observation that red meat consumption is related to higher risk of diabetes independent of dietary fat ${ }^{(43,44)}$ highlights the possibility that protein-rich foods, particularly red meat, may adversely affect carbohydrate metabolism. It remains, however, unclear why the substitution of carbohydrates for PUFA was related to lower diabetes risk in the present study. Such substitution is expected to result in a decrease in HDL-cholesterol ${ }^{(12)}$ which should lead to higher diabetes risk $^{(9-11)}$. In addition, higher carbohydrate intake is inversely related to adiponectin concentrations $^{(45)}$, and, in contrast, intake of $n-3$ PUFA may up regulate adiponectin secretion ${ }^{(13)}$. Thus, substituting carbohydrates for PUFA would be expected to result in lower adiponectin concentrations, increased insulin resistance, and increased risk of diabetes ${ }^{(14)}$. However, PUFA intake has not been consistently shown to be related to lower diabetes risk $^{(32,46,47)}$ and long-chain $n$-3 PUFA even with an increased risk $^{(46)}$. We were not able to distinguish between cis- and trans-PUFA which have very different physiological consequences ${ }^{(48)}$. Thus, interpretation of our observations should be made cautiously.

All potential cases in the present study were verified through the treating physician. Given the resulting high positive predictive value of the disease classification, the remaining misclassification (non-identified cases) should not have biased the estimated risk ${ }^{(49)}$. However, we considered
(A) Carbohydrate-for-fat substitution

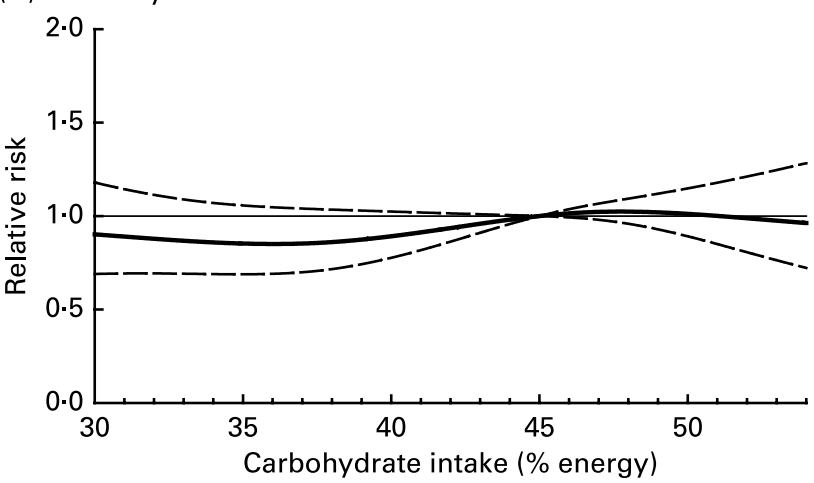

(B) Carbohydrate-for-protein substitution

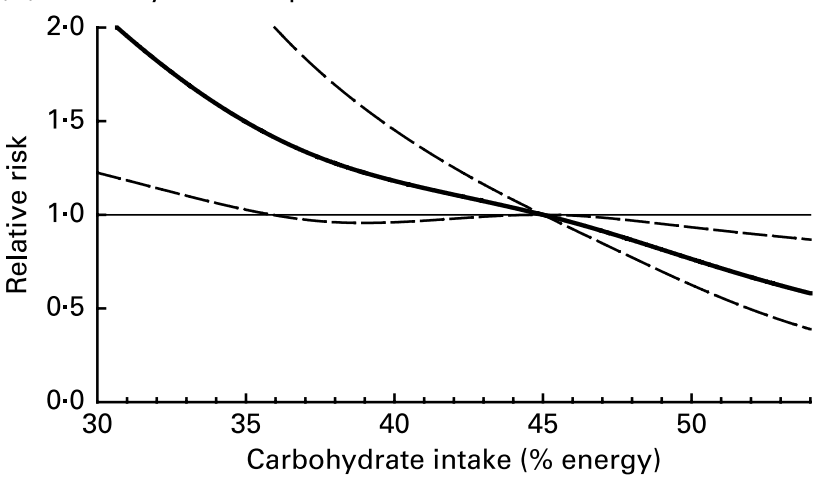

(C) Carbohydrate-for-PUFA substitution

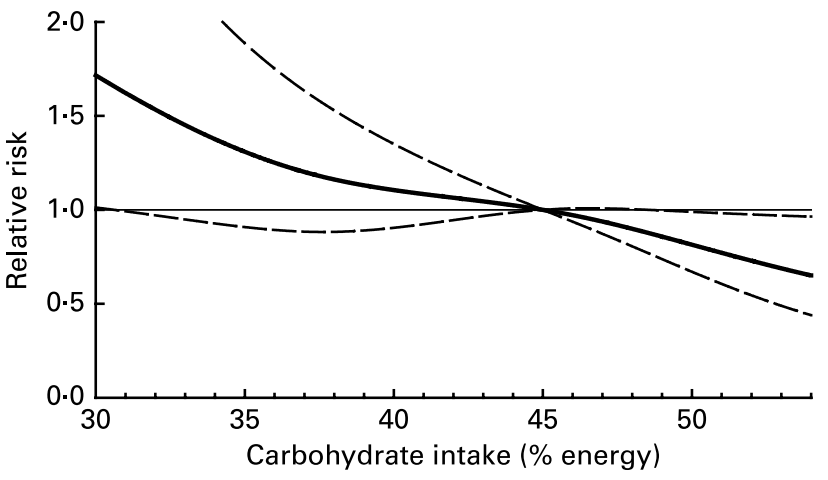

Fig. 3. Relative risk of type 2 diabetes for isoenergetic substitution of energy with carbohydrates for total fat (A), protein (B) and PUFA (C) among participants in the European Prospective Investigation into Cancer and NutritionPotsdam Study, 2005. Lines are restricted cubic splines showing the shape of dose-response curve according to carbohydrate intake on a continuous basis: relative risks (-); $95 \% \mathrm{Cl}(---)$. The reference point is $45 \%$ energy from carbohydrates with knots placed at the 5 th $(31.1 \%$ energy), 25th (37.6\% energy), 75 th ( $46 \cdot 3 \%$ energy) and 95th percentile (52.5\% energy) of carbohydrate intake distribution. All models were adjusted for age, sex, education (in or no training, vocational training, technical school, or technical college or university degree), occupational activity (light, moderate, heavy), sport activity $(0,0.1-4.0,>4.0 \mathrm{~h} /$ week $)$, cycling $(0,0.1-2.4,2.5-4.9, \geq 5 \mathrm{~h} /$ week), smoking (never, past, current $<20$ cigarettes/d, current $\geq 20$ cigarettes/d), alcohol intake, total energy intake, fibre intake, Mg intake, PUFA:SFA ratio, and MUFA:SFA ratio.

only clinically apparent type 2 diabetes and did not screen our study population for diabetes at baseline, thus it is possible that prevalent but undiagnosed cases of diabetes remained in our analyses. The glycaemic index, a measure 
of carbohydrate quality in terms of quantified glucose response to foods, is not available in the German Food Code and Nutrient Data Base version II. $3^{(21)}$. Therefore, we were not able to address whether the association between carbohydrate intake and diabetes risk is independent or may be modified by the carbohydrate quality in terms of quantified glucose response to particular foods, for example, the glycaemic index and load. While we controlled in our analyses for fibre, $\mathrm{Mg}$ and fat quality, other nutrients related to carbohydrate intake may account for the associations. The potential of residual confounding due to unknown factors or incomplete statistical control applies to the present study as to observational studies in general. It is therefore possible that other factors may explain the observed associations or that they may mask potential associations. Although we calibrated FFQ data to the mean and variance of estimated habitual dietary intake from $24 \mathrm{~h}$ recalls, thus allowing quantitative analyses of the FFQ data, there is a significant degree of error in measuring dietary carbohydrate intake with our FFQ. In addition, it is possible that participants in the present study changed their dietary intake after the baseline measurement. Random measurement error and the lack of repeated measurement of diet may have led to an underestimation of association ${ }^{(50)}$. Furthermore, adjustment for energy intake, body weight and waist circumference may reflect adjustment for covariates being on the causal pathway between carbohydrate intake and diabetes risk, thus representing an over-adjustment. However, we are not able to clarify whether body fatness is a mediator or confounder in the present study. Adjustment allows us not only to control for a potential confounding effect of body fatness but also to control for the effect of selective underreporting of fat and energy intake which has been related to obesity in our study $^{(51)}$ and in other studies ${ }^{(52)}$. Still, our observations remained similar when we did not control for energy intake, BMI and waist circumference, supporting that substitutions of carbohydrates for PUFA or protein might have physiological consequences beyond excessive energy intake and weight gain. Although the present study involved a relatively large number of incident cases, it might have been underpowered to detect associations within specific subgroups. For example, although inverse associations were observed for carbohydrate-for-protein and carbohydratefor-PUFA substitutions in the full cohort, only the carbohydrate-for-protein substitution among men gained significance in sex-specific analyses. Because spline regression did not indicate non-linear associations and the inverse association was observable across subgroups of sex, BMI, carbohydrate intake, and the reported energy intake:BMR ratio, the nonsignificance within subgroups might reflect the limited power of such analyses rather than the absence of these associations. Although we had considerable variation in carbohydrate intake in our cohort (5th percentile, $31.1 \%$ energy; median, $42.1 \%$ energy; 95 th percentile, $52.5 \%$ energy), we were not able to reliably estimate associations for macronutrient substitutions at very low or very high carbohydrate intakes. We did not evaluate foods or food groups that are rich in carbohydrates or rich in protein or PUFA and that might widely vary in their nutrient composition. Thus, translation of our findings into food-based dietary guidelines is limited. 
Table 4. Relative risk (RR) of type 2 diabetes by quintiles of carbohydrate intake among men and women in the European Prospective Investigation into Cancer and Nutrition-Potsdam Study, 2005

\begin{tabular}{|c|c|c|c|c|c|c|c|c|c|c|c|c|}
\hline & \multicolumn{6}{|c|}{ Men } & \multicolumn{6}{|c|}{ Women } \\
\hline & \multicolumn{5}{|c|}{ Quintiles of carbohydrate intake $(\mathrm{g} / \mathrm{d})$} & \multirow[b]{2}{*}{$P$} & \multicolumn{5}{|c|}{ Quintiles of carbohydrate intake $(\mathrm{g} / \mathrm{d})$} & \multirow[b]{2}{*}{$P$} \\
\hline & 1 & 2 & 3 & 4 & 5 & & 1 & 2 & 3 & 4 & 5 & \\
\hline \multicolumn{13}{|l|}{ Starch } \\
\hline Median (g/d) & 71.0 & 93.8 & 110.9 & 129.5 & 161.4 & \multirow{4}{*}{0.260} & 51.9 & 69.5 & 82.9 & 97.5 & $122 \cdot 3$ & \multirow{4}{*}{0.332} \\
\hline Cases $(n)$ & 116 & 110 & 100 & 89 & 76 & & 72 & 77 & 76 & 65 & 65 & \\
\hline $\mathrm{RR}^{\star}$ & 1.00 & 0.99 & 0.90 & 0.87 & 0.79 & & 1.00 & 1.06 & 1.02 & 0.94 & 1.38 & \\
\hline $95 \% \mathrm{Cl}$ & & $0.75,1.31$ & $0.66,1.23$ & $0.60,1.24$ & $0.50,1.24$ & & & $0.75,1.49$ & $0.71,1.47$ & $0.62,1.43$ & $0 \cdot 84,2 \cdot 26$ & \\
\hline \multicolumn{13}{|l|}{ Sucrose } \\
\hline Median (g/d) & 22.5 & 37.6 & 51.0 & 67.7 & $102 \cdot 0$ & \multirow{4}{*}{0.063} & 28.2 & $39 \cdot 3$ & 48.5 & $60 \cdot 3$ & 83.4 & \multirow{4}{*}{0.492} \\
\hline Cases $(n)$ & 119 & 109 & 101 & 83 & 79 & & 85 & 69 & 62 & 61 & 78 & \\
\hline $\mathrm{RR}^{\star}$ & 1.00 & 0.96 & 0.98 & 0.85 & 0.72 & & 1.00 & 0.89 & 0.86 & 0.90 & 1.13 & \\
\hline $95 \% \mathrm{Cl}$ & & $0.73,1.26$ & $0.74,1.31$ & $0.62,1.17$ & $0.50,1.04$ & & & $0.64,1.24$ & $0.60,1.22$ & $0.62,1.31$ & $0.74,1.74$ & \\
\hline \multicolumn{13}{|l|}{ Glucose } \\
\hline Median (g/d) & 6.6 & $11 \cdot 1$ & $15 \cdot 0$ & $20 \cdot 2$ & 31.4 & \multirow{4}{*}{0.721} & $9 \cdot 6$ & $13 \cdot 1$ & $15 \cdot 4$ & $18 \cdot 1$ & $24 \cdot 3$ & \\
\hline Cases $(n)$ & 106 & 99 & 96 & 77 & 113 & & 62 & 62 & 100 & 69 & 62 & \multirow{3}{*}{0.599} \\
\hline $\mathrm{RR}^{*}$ & 1.00 & 1.05 & 1.06 & 0.87 & $1 \cdot 10$ & & 1.00 & 0.78 & 1.09 & 0.81 & 0.88 & \\
\hline $95 \% \mathrm{Cl}$ & & $0.79,1.40$ & $0.79,1.42$ & $0.63,1.19$ & $0.81,1.50$ & & & $0.52,1.15$ & $0.75,1.60$ & $0.53,1.22$ & $0.58,1.33$ & \\
\hline \multicolumn{13}{|l|}{ Fructose } \\
\hline Median (g/d) & 8.4 & 14.4 & 19.9 & $26 \cdot 6$ & $40 \cdot 6$ & \multirow{4}{*}{0.987} & $11 \cdot 0$ & $15 \cdot 8$ & $19 \cdot 9$ & $25 \cdot 0$ & 34.8 & \multirow{4}{*}{0.877} \\
\hline Cases $(n)$ & 111 & 97 & 82 & 89 & 112 & & 78 & 72 & 71 & 55 & 79 & \\
\hline $\mathrm{RR}^{*}$ & 1.00 & 1.03 & 0.84 & 0.94 & 1.00 & & 1.00 & $1 \cdot 18$ & 1.04 & 0.76 & 1.09 & \\
\hline $95 \% \mathrm{Cl}$ & & $0.78,1.36$ & $0.63,1.14$ & $0.70,1.27$ & $0.74,1.35$ & & & $0.85,1.65$ & $0.73,1.46$ & $0.52,1 \cdot 11$ & $0.75,1.58$ & \\
\hline
\end{tabular}

${ }^{*}$ Adjusted for age, sex, education (in or no training, vocational training, technical school, or technical college or university degree), occupational activity (light, moderate, heavy), sport activity (0, $0.1-4.0,>4.0 \mathrm{~h} /$ week), cycling $(0,0 \cdot 1-2 \cdot 4,2 \cdot 5-4 \cdot 9, \geq 5 \mathrm{~h} /$ week), smoking (never, past, current $<20$ cigarettes/d, current $\geq 20$ cigarettes/d), alcohol intake, total energy intake, BMI, waist circumference, fibre intake, Mg intake, PUFA:SFA ratio, and MUFA:SFA 
In conclusion, a higher carbohydrate intake at the expense of protein and PUFA might be associated with decreased diabetes risk.

\section{Acknowledgements}

The recruitment phase of the EPIC-Potsdam Study was supported by the Federal Ministry of Science, Germany (01 EA 9401) and the European Union (SOC 95201408 05F02). The follow-up of the EPIC-Potsdam Study was supported by German Cancer Aid (70-2488-Ha I) and the European Community (SOC 98200769 05F02). M. B. S. was partly supported by the European Union (FP6-2005-513946). M. B. S. contributed to the development of the analysis plan, conducted the statistical analyses, collaborated on the interpretation of the results and wrote the manuscript. K. H. and H. B. provided significant consultation on the statistical analysis plan, interpretation of results and writing of the manuscript. M. S., C. H. and A. S. provided significant consultation on the interpretation of results and writing of the manuscript. None of the authors had any financial or personal interest in any company or organisation sponsoring this research, including advisory board affiliations.

Kurt Hoffmann died during the review process of the manuscript and the authors would like to dedicate this paper to our colleague and friend.

\section{References}

1. Hu FB, Manson JE, Stampfer MJ, Colditz G, Liu S, Solomon CG \& Willett WC (2001) Diet, lifestyle, and the risk of type 2 diabetes mellitus in women. $N$ Engl J Med 345, 790-797.

2. Schulze MB \& Hu FB (2005) Primary prevention of diabetes: what can be done and how much can be prevented? Annu Rev Public Health 26, 445-467.

3. Salmeron J, Ascherio A, Rimm EB, Colditz GA, Spiegelman D, Jenkins DJ, Stampfer MJ, Wing AL \& Willett WC (1997) Dietary fiber, glycemic load, and risk of NIDDM in men. Diabetes Care 20, 545-550.

4. Salmeron J, Manson JE, Stampfer MJ, Colditz GA, Wing AL \& Willett WC (1997) Dietary fiber, glycemic load, and risk of non-insulin-dependent diabetes mellitus in women. JAMA 277, $472-477$.

5. Meyer KA, Kushi LH, Jacobs DR Jr, Slavin J, Sellers TA \& Folsom AR (2000) Carbohydrates, dietary fiber, and incident type 2 diabetes in older women. Am J Clin Nutr 71, 921-930.

6. Hodge AM, English DR, O'Dea K \& Giles GG (2004) Glycemic index and dietary fiber and the risk of type 2 diabetes. Diabetes Care 27, 2701-2706.

7. Schulze MB, Liu S, Rimm EB, Manson JE, Willett WC \& Hu FB (2004) Glycemic index, glycemic load, and dietary fiber intake and incidence of type 2 diabetes in younger and middle-aged women. Am J Clin Nutr 80, 348-356.

8. Schulz M, Liese AD, Fang F, Gilliard TS \& Karter AJ (2006) Is the association between dietary glycemic index and type 2 diabetes modified by waist circumference? Diabetes Care 29, $1102-1104$

9. Fagot-Campagna A, Narayan KM, Hanson RL, Imperatore G, Howard BV, Nelson RG, Pettitt DJ \& Knowler WC (1997) Plasma lipoproteins and incidence of non-insulin-dependent diabetes mellitus in Pima Indians: protective effect of HDL cholesterol in women. Atherosclerosis 128, 113-119.

10. Njolstad I, Arnesen E \& Lund-Larsen PG (1998) Sex differences in risk factors for clinical diabetes mellitus in a general population: a 12-year follow-up of the Finnmark Study. Am J Epidemiol 147, 49-58.

11. Fagot-Campagna A, Knowler WC, Narayan KM, Hanson RL, Saaddine J \& Howard BV (1999) HDL cholesterol subfractions and risk of developing type 2 diabetes among Pima Indians. Diabetes Care 22, 271-274.

12. Mensink RP, Zock PL, Kester AD \& Katan MB (2003) Effects of dietary fatty acids and carbohydrates on the ratio of serum total to HDL cholesterol and on serum lipids and apolipoproteins: a meta-analysis of 60 controlled trials. Am J Clin Nutr 77, 1146-1155.

13. Neschen S, Morino K, Rossbacher JC, Pongratz RL, Cline GW, Sono S, Gillum M \& Shulman GI (2006) Fish oil regulates adiponectin secretion by a peroxisome proliferator-activated receptor- $\{\gamma\}$-dependent mechanism in mice. Diabetes 55, 924-928.

14. Hara K, Yamauchi $T$ \& Kadowaki $T$ (2005) Adiponectin: an adipokine linking adipocytes and type 2 diabetes in humans. Curr Diab Rep 5, 136-140.

15. Nuttall FQ, Mooradian AD, Gannon MC, Billington C \& Krezowski P (1984) Effect of protein ingestion on the glucose and insulin response to a standardized oral glucose load. Diabetes Care 7, 465-470.

16. Simpson RW, McDonald J, Wahlqvist ML, Atley L \& Outch K (1985) Macronutrients have different metabolic effects in nondiabetics and diabetics. Am J Clin Nutr 42, 449-453.

17. Hu FB, Stampfer MJ, Manson JE, Rimm E, Colditz GA, Rosner BA, Hennekens CH \& Willett WC (1997) Dietary fat intake and the risk of coronary heart disease in women. $N$ Engl J Med 337, $1491-1499$

18. Faerch K, Lau C, Tetens I, Pedersen OB, Jorgensen T, BorchJohnsen K \& Glumer C (2005) A statistical approach based on substitution of macronutrients provides additional information to models analyzing single dietary factors in relation to type 2 diabetes in Danish adults: the Inter99 study. $J$ Nutr 135, 1177-1182.

19. Boeing H, Wahrendorf J \& Becker N (1999) EPIC-Germany - a source for studies into diet and risk of chronic diseases. Ann Nutr Metab 43, 195-204.

20. Boeing H, Korfmann A \& Bergmann MM (1999) Recruitment procedures of EPIC-Germany. European Investigation into Cancer and Nutrition. Ann Nutr Metab 43, 205-215.

21. Dehne LI, Klemm C, Henseler G \& Hermann-Kunz E (1999) The German Food Code and Nutrient Data Base (BLS II.2). Eur J Epidemiol 15, 355-359.

22. Slimani N, Ferrari P, Ocke M, et al. (2000) Standardization of the 24-hour diet recall calibration method used in the European Prospective Investigation into Cancer and Nutrition (EPIC): general concepts and preliminary results. Eur J Clin Nutr 54, 900-917.

23. Kynast-Wolf G, Becker N, Kroke A, Brandstetter BR, Wahrendorf J \& Boeing H (2002) Linear regression calibration: theoretical framework and empirical results in EPIC, Germany. Ann Nutr Metab 46, 2-8.

24. Willett WC, Howe GR \& Kushi LH (1997) Adjustment for total energy intake in epidemiologic studies. Am J Clin Nutr 65, Suppl. 4, 1220S-1228S.

25. Kroke A, Klipstein-Grobusch K, Voss S, Moseneder J, Thielecke F, Noack R \& Boeing H (1999) Validation of a self-administered food-frequency questionnaire administered in the European Prospective Investigation into Cancer and Nutrition (EPIC) Study: comparison of energy, protein, and macronutrient intakes estimated with the doubly labeled water, urinary nitrogen, and repeated 24-h dietary recall methods. Am J Clin Nutr 70, 439-447.

26. Bohlscheid-Thomas S, Hoting I, Boeing $\mathrm{H} \&$ Wahrendorf $\mathrm{J}$ (1997) Reproducibility and relative validity of energy and macronutrient intake of a food frequency questionnaire developed for the German part of the EPIC project. European 
Prospective Investigation into Cancer and Nutrition. Int $J$ Epidemiol 26, Suppl. 1, S71-S81.

27. Kroke A, Bergmann MM, Lotze G, Jeckel A, KlipsteinGrobusch K \& Boeing H (1999) Measures of quality control in the German component of the EPIC study. European Prospective Investigation into Cancer and Nutrition. Ann Nutr Metab 43, 216-224.

28. Klipstein-Grobusch K, Georg T \& Boeing H (1997) Interviewer variability in anthropometric measurements and estimates of body composition. Int J Epidemiol 26, Suppl. 1, S174-S180.

29. Willett W \& Lenart E (1998) Implications of total energy intake for epidemiologic analyses. In Nutritional Epidemiology, pp. 273-301 [W Willett, editor]. New York: Oxford University Press.

30. Harrell FE Jr, Lee KL \& Pollock BG (1988) Regression models in clinical studies: determining relationships between predictors and response. J Natl Cancer Inst 80, 1198-1202.

31. Heinzl H \& Kaider A (1997) Gaining more flexibility in Cox proportional hazards regression models with cubic spline functions. Comput Methods Programs Biomed 54, 201-208.

32. Salmeron J, Hu FB, Manson JE, Stampfer MJ, Colditz GA, Rimm EB \& Willett WC (2001) Dietary fat intake and risk of type 2 diabetes in women. Am J Clin Nutr 73, 1019-1026.

33. Janket SJ, Manson JE, Sesso H, Buring JE \& Liu S (2003) A prospective study of sugar intake and risk of type 2 diabetes in women. Diabetes Care 26, 1008-1015.

34. Colditz GA, Manson JE, Stampfer MJ, Rosner B, Willett WC \& Speizer FE (1992) Diet and risk of clinical diabetes in women. Am J Clin Nutr 55, 1018-1023.

35. Daly M (2003) Sugars, insulin sensitivity, and the postprandial state. Am J Clin Nutr 78, 865S-872S.

36. Schulze MB, Manson JE, Ludwig DS, Colditz GA, Stampfer MJ, Willett WC \& Hu FB (2004) Sugar-sweetened beverages, weight gain, and incidence of type 2 diabetes in young and middle-aged women. JAMA 292, 927-934.

37. Linn T, Santosa B, Gronemeyer D, Aygen S, Scholz N, Busch M \& Bretzel RG (2000) Effect of long-term dietary protein intake on glucose metabolism in humans. Diabetologia 43, 1257-1265.

38. Krebs M, Brehm A, Krssak M, et al. (2003) Direct and indirect effects of amino acids on hepatic glucose metabolism in humans. Diabetologia 46, 917-925.

39. Krebs M, Krssak M, Bernroider E, Anderwald C, Brehm A, Meyerspeer M, Nowotny P, Roth E, Waldhausl W \& Roden
M (2002) Mechanism of amino acid-induced skeletal muscle insulin resistance in humans. Diabetes 51, 599-605.

40. Krebs M (2005) Amino acid-dependent modulation of glucose metabolism in humans. Eur J Clin Invest 35, 351-354.

41. Bravata DM, Sanders L, Huang J, Krumholz HM, Olkin I \& Gardner CD (2003) Efficacy and safety of low-carbohydrate diets: a systematic review. JAMA 289, 1837-1850.

42. Katan MB (2006) Alternatives to low-fat diets. Am J Clin Nutr 83, 989-990.

43. Schulze MB, Manson JE, Willett WC \& Hu FB (2003) Processed meat intake and incidence of type 2 diabetes in younger and middle-aged women. Diabetologia 46, 1465-1473.

44. Song Y, Manson JE, Buring JE \& Liu S (2004) A prospective study of red meat consumption and type 2 diabetes in middleaged and elderly women: The Women's Health Study. Diabetes Care 27, 2108-2115.

45. Pischon T, Girman CJ, Rifai N, Hotamisligil GS \& Rimm EB (2005) Association between dietary factors and plasma adiponectin concentrations in men. Am J Clin Nutr 81, 780-786.

46. Meyer KA, Kushi LH, Jacobs DR Jr \& Folsom AR (2001) Dietary fat and incidence of type 2 diabetes in older Iowa women. Diabetes Care 24, 1528-1535.

47. van Dam RM, Willett WC, Rimm EB, Stampfer MJ \& Hu FB (2002) Dietary fat and meat intake in relation to risk of type 2 diabetes in men. Diabetes Care 25, 417-424.

48. Mozaffarian D, Katan MB, Ascherio A, Stampfer MJ \& Willett WC (2006) Trans fatty acids and cardiovascular disease. $N$ Engl J Med 354, 1601-1613.

49. Greenland S (1998) Basic methods for sensitivity analysis and external adjustment. In Modern Epidemiology, 2nd ed. pp. 343-358 [JR Rothman and S Greenland, editors]. Philadelphia, PA: Lippincott-Raven.

50. Hu FB, Stampfer MJ, Rimm E, Ascherio A, Rosner BA, Spiegelman D \& Willett WC (1999) Dietary fat and coronary heart disease: a comparison of approaches for adjusting for total energy intake and modeling repeated dietary measurements. Am J Epidemiol 149, 531-540.

51. Voss S, Kroke A, Klipstein-Grobusch K \& Boeing H (1997) Obesity as a major determinant of underreporting in a self-administered food frequency questionnaire: results from the EPICPotsdam Study. Z Ernahrungswiss 36, 229-236.

52. Livingstone MB \& Black AE (2003) Markers of the validity of reported energy intake. J Nutr 133, Suppl. 3, 895S-920S. 